\title{
Programa de abordagem interdisciplinar no tratamento do transtorno de personalidade borderline - relato da experiência no ambulatório Melanie Klein do Hospital Psiquiátrico São Pedro
}

\author{
Adriana Dal'Pizol* \\ Liliane Dias de Lima** \\ Leticia Medeiros Ferreira*** \\ Milene Calderaro Martins ${ }^{* * *}$ \\ Pablo de Oliveira Corrêa ${ }^{* * * *}$ \\ Míriam Alves ${ }^{* \star * \star *}$ \\ Sílvia Giuliani******* \\ Vanessa Buttes ${ }^{\star * * * * * *}$
}

\section{INTRODUÇÃO}

"Ser capaz de tolerar tudo o que podemos encontrar em nossa realidade interior é uma das grandes dificuldades humanas, e um dos importantes objetivos humanos

\footnotetext{
* Médica psiquiatra, Coordenadora do Programa de Atendimento a Portadores de Transtorno de Personalidade Emocionalmente Instável do Tipo Limítrofe do Ambulatório Melanie Klein, Hospital Psiquiátrico São Pedro.

** Médica psiquiatra, doutoranda em Psicologia Social pela PUCRS, Coordenadora do Ambulatório Melanie Klein do HPSP, Hospital Psiquiátrico São Pedro/Escola de Saúde Pública do Rio Grande do Sul.

${ }^{* * *}$ Médica psiquiatra.

**** Terapeuta ocupacional, Especialista em Saúde Mental Coletiva pela Escola de Saúde Pública do Rio Grande do Sul/Hospital Psiquiátrico São Pedro.

***** Médico Psiquiatra, Mestrando em Antropologia Social pela Universidade Federal do Rio Grande do Sul

****** Educadora Física, Especialista em Saúde Mental Coletiva pela Escola de Saúde Pública do Rio Grande do Sul/Hospital Psiquiátrico São Pedro, Mestranda em Psicologia Social pela PUCRS.

******* Assistente social, Especialista em Saúde Mental Coletiva pela Escola de Saúde Pública do Rio Grande do Sul/Hospital Psiquiátrico São Pedro.

******** Psicóloga, Especialista em Saúde Mental Coletiva pela Escola de Saúde Pública do Rio Grande do Sul/Hospital Psiquiátrico São Pedro.
}

consiste em estabelecer relações harmoniosas entre as realidades pessoais internas e as realidades exteriores."

Winnicott ${ }^{1}$

O Transtorno de Personalidade Borderline ocorre em 2 a $3 \%$ da população geral, e é de longe o transtorno de personalidade mais comum. Entre os pacientes psiquiátricos estimase que ocorra em $11 \%$ das populações não hospitalizadas, $19 \%$ das populações hospitalizadas e 27 a $63 \%$ das populações clínicas com transtorno de personalidade ${ }^{2}$.

O termo borderline foi inicialmente usado para identificar pacientes que evocavam fortes reações de contratransferência em seus terapeutas e que pareciam regredir na ausência das estruturas externas que eles tentavam evitar. Foram descritos pela primeira vez por Stern (in Kernberg, 1995), que os identificou no exercício da psicoterapia, e posteriormente por Robert Knight, que os identificou em pacientes hospitalizados. $O$ interesse nesses pacientes aumentou no final da década de 60 , quando Kernberg e James Masterson sugeriram que eles podiam ser curados por psicoterapia inten- 
siva de longo prazo ou tratamento hospitalar. O aumento do empenho terapêutico foi acompanhado por pesquisas de fenomenologia, cujo pioneiro foi Roy Grinker, seguido de John Gunderson, as quais permitiram a identificação de características discriminantes. Estas características tornaram-se critérios diagnósticos após um grande estudo realizado por Robert Spitzer e seus colegas, e que demonstrou sua ampla aplicabilidade a pacientes na prática psiquiátrica. As teorias modernas sobre o constructo falam de fatores genéticos inespecíficos, mas talvez mais específicos sejam os problemas do desenvolvimento associados com negligência emocional e, freqüentemente, abuso na infância.

Os pacientes com transtorno borderline de personalidade são severamente disfuncionais. Seu quadro clínico está intimamente ligado ao contexto interpessoal no qual eles são observados; a maioria dos aspectos observáveis do transtorno são altamente sensíveis ao estresse da realidade externa e interpessoal. Por exemplo, do contexto de uma relação de apoio (ou dentro de um ambiente de suporte estruturado), os aspectos de sedução, carência e distimia são evidentes. Contudo, a percepção da perda iminente de tal relação ou estrutura pode provocar raiva súbita, acusações depreciativas ou paranóides e atos autodestrutivos a provocar respostas protetoras. $\mathrm{Na}$ ausência de um relacionamento, episódios dissociativos, abuso de substâncias e comportamento impulsivo, desesperado, pode ocorrer.

A psicoterapia individual de longo prazo pode ser útil para pacientes com transtorno de personalidade borderline, mas a maioria das psicoterapias são interrompidas tempestuosa e impulsivamente. A psicoterapia de curto prazo pode ser útil para manejar crises ou para introduzir formas de terapia de longo prazo. A psicanálise algumas vezes pode ser contra-indicada, porque os pacientes regridem facilmente em resposta à sua falta de estrutura. Uma ampla variedade de tratamentos coadjuvantes é freqüentemente necessária para manter e aumentar os benefícios da terapia individual. Hospitalizações intermitentes, em geral breves, são comuns.

O tratamento farmacológico é variado e seus efeitos são inconsistentes e, às vezes, modestos e deve ser considerada a probabilidade de abuso e efeitos colaterais, devendo se ter cautela em sua prescrição.

O Ambulatório Melanie Klein do Hospital Psiquiátrico São Pedro caracteriza-se por assistir e tratar portadores de sofrimento psíquico grave, entre eles aqueles que têm diagnóstico de transtorno de personalidade borderline. Tendo em vista que o Ambulatório está inserido como campo de estágio da Residência Integrada em Saúde Mental e tem como prática terapêutica a ação interdisciplinar, os técnicos pesquisadores observaram a necessidade de encontrar uma abordagem terapêutica para tentar a estabilização desses pacientes. Para isso, foi criado um Programa de Atendimento Interdisciplinar a Portadores de Transtorno de Personalidade Emocionalmente Instável do Tipo Limítrofe. O objetivo deste trabalho é descrever esta experiência e os resultados obtidos, utilizando como exemplo o relato de dois casos clínicos atendidos na modalidade interdisciplinar proposta.

\section{O TRANSTORNO DE PERSONALIDADE BORDERLINE}

Os transtornos de personalidade são uma classe diagnóstica em Psiquiatria que causa muita discussão e ainda algumas controvérsias. O próprio conceito de personalidade varia muito nas conceituações que apresenta, pois surgiu no século 4 a. C. ${ }^{2}$ Em sua definição, tanto a Décima Edição da Classificação Internacional das Doenças (CID-10) ${ }^{3}$ quanto o Manual Diagnóstico e Estatístico de Transtornos Mentais (DSM-IV) ${ }^{4}$ apontam para o fato destes transtornos serem um padrão global de alterações que perduram cronologicamente. Isto leva a um desafio no diagnóstico destas condições, pois, exige, na maioria dos casos, uma observação acurada e um acompanhamento mais extenso.

O transtorno de personalidade borderline, assim intitulado no DSM-IV4 (ver tabela 1), é denominado na CID-10 como Transtorno de personalidade emocionalmente instável, tipo borderline (limítrofe) (ver tabela 2). Em ambas classificações, é caracterizado por padrão difuso de instabilidade dos relacionamentos interpessoais, da auto-imagem e dos afetos e acentuada impulsividade, começando no início da vida adulta e presente em uma variedade de contextos.

Sua prevalência na população geral varia entre 1,8 e $4 \%$ segundo um autor ${ }^{5}$ e entre 2 e $3 \%$ segundo outros ${ }^{6}$. É considerado o transtorno mais comum entre populações clínicas psiquiátricas, com prevalência entre 15 e $25 \%$ nestas populações ${ }^{7}$.

Segundo López ${ }^{8}$, em seu trabalho: "Síndrome Fronterizo: cuerpo, encuadre y discurso", a definição de limítrofe inclui a presença da frag- 
mentação do aparelho psíquico com seu possível desenlace em grupos de pacientes: 1. os que apresentam fortes tendências para socialização das angústias psicóticas; 2 . os que desenvolvem fortes sintomatologia neurótica; 3 . os que utilizam o corpo como depositário dos vínculos delirantes. Existe um quarto grupo, demasiado próximo das toxicomanias, das psicopatias e da compulsividade em geral ${ }^{8}$.

Kernberg e colaboradores ${ }^{9}$ descrevem o funcionamento psicodinâmico destes pacientes a partir de três critérios: difusão de identidade, nível de operações defensivas e capacidade de teste de realidade. A difusão de identidade caracteriza-se como falta de integração do conceito de self e de outros significativos. Ela mostra-se na experiência subjetiva do paciente como sensação de vazio crônico, contradição nas percepções sobre si, atitudes contraditórias. As operações defensivas concentram-se nas defesas primitivas, centradas no mecanismo de clivagem. Para proteger o ego do conflito, são utilizadas idealização primitiva, identificação projetiva, denegação, controle onipotente e desvalorização. Em relação ao teste de realidade, os autores afirmam que os portadores deste transtorno têm a capacidade de teste de realidade mantida, mas possuem alterações na sua relação com a realidade, ou seja, a realidade é adequadamente avaliada, mas o comportamento é inapropriado e incoerente com a avaliação da realidade.

O paciente limítrofe tem dificuldades laborais, conjugais e/ou para vencer as etapas habituais da vida. Pode psicotizar numa situação de estresse que o neurótico enfrentaria com mais êxito. A maior parte dos quadros que parecem ser neuroses "muito típicas" costuma ser de transtornos limítrofes: as histerias graves, bizarras; as neuroses obsessivas que se limitam com a psicose ou certas fobias graves, com grande infiltração de pensamento delirante ${ }^{8}$.

Também são apresentadas características estruturais secundárias desta organização de personalidade. Manifestações de fraqueza egóica, patologias do superego e relações objetais cronicamente caóticas seriam conseqüências diretas da difusão de identidade e do predomínio de operações defensivas imaturas.

\section{A prática Interdisciplinar}

Para atender às diversas demandas do paciente com Transtorno Borderline de Personalidade, o qual apresenta alterações em diversas áreas de suas vidas, faz-se necessário estabelecer uma abordagem terapêutica que contem- ple as diversas dimensões desses sujeitos. Aqui, enfoca-se o conceito de integralidade. Este seria o fundamento epistemológico refletido em uma prática interdisciplinar.

A integralidade é uma das diretrizes do Sistema Único de Saúde instituído pela Constituição de 1988. O texto constitucional, em seu artigo 198, refere-se a "atendimento integral, com prioridade para as atividades preventivas, sem prejuízo dos serviços assistenciais" "10.

Disponibilizar o atendimento integral para um sujeito significa aceitar que existem limitações em relação à disciplina que um profissional domina e reconhecer que nenhum campo do saber pode dar conta das diversas dimensões daquele indivíduo. Assim, é aberto o espaço para a interdisciplinaridade: aceitar que o indivíduo jamais é abrangido com exclusividade por algum saber específico, ou seja, por apenas uma especialidade, e que só com a integração desses vários saberes poderemos de fato nos aproximar da multidimensionalidade de cada sujeito.

Ruben Araújo de Mattos ${ }^{11}$ aponta para três sentidos da integralidade em saúde. O primeiro seria "integralidade como um traço da boa medicina", ou seja, uma atitude dos profissionais de saúde que não se limita a reduzir um indivíduo a um sistema biológico disfuncional. Como exemplo, Mattos ${ }^{11}$ cita o médico que "aproveita o encontro para apreciar fatores de risco de outras doenças que não as envolvidas no sofrimento concreto daquele paciente e/ou investigar a presença de doenças que ainda não se expressaram em sofrimento".

Outro sentido deste conceito está relacionado ao modo de organização dos serviços de saúde. Mattos ${ }^{11}$ ressalta que os serviços devem estar sempre abertos a contemplar a multiplicidade de necessidades expressadas por seus usuários, o que interfere no modo como são planejados.

O terceiro significado apontado pelo autor refere-se às ações governamentais relativas aos problemas de saúde. Uma ação governamental considerada integral traria uma "recusa a reduzir a objetos descontextualizados, os sujeitos sobre os quais as políticas incidem"11.

O conceito de prática interdisciplinar apontado neste estudo também se concentra em dois fatores principais: atitude dos profissionais de saúde e organização dos serviços. Eles devem estar em harmonia para que uma prática integradora dos saberes ocorra. O profissional de saúde deve estar aberto ao compartilhar de seus conhecimentos e experiências, bem como 
disposto a aprender com os conhecimentos e experiências de outros profissionais. A fragmentação dos saberes em disciplinas que este profissional representa e de que é representante, configurada como um habitus, ou seja, modelos de ação internalizados e reproduzidos, torna essas práticas cotidianas vinculadas ao espírito da modernidade, principalmente a partir da relação entre o sujeito e o imaginário social que porta dentro de si.

Segundo Castoriadis' ${ }^{12}$, as significações imaginárias constituem as sociedades, suas justificativas, as maneiras como essa sociedade compreende a si mesma. Isto se evidencia na relação entre os diferentes profissionais e também de quem atende e quem é atendido, indivíduo e sociedade, remetendo-nos à lógica normativa, o que rompe a integralidade da ação em saúde.

A interdisciplina nasce na década de 70 como resposta aos vários problemas surgidos da legitimação do capitalismo. Na época, discutia-se a divisão entre teoria e prática e o pouco conteúdo social que subsidiava os currículos universitários. Por estas e outras exigências da situação, que acabou mobilizando principalmente os estudantes universitários que lançaram mão de posições anticapitalistas, as instituições acadêmicas tradicionais deram certo lugar a essa demanda, absorvendo seu potencial crítico de forma a, muito sutilmente, transformar seu significado. Deste momento em diante, houve algumas mudanças tanto na estrutura quanto no modo de funcionamento das Universidades européias e após também na América Latina.

A interdisciplina seguiu se caracterizando como recurso importante no planejamento de estratégias. Desse modo, chegou-se à hipótese de que a interdisciplina poderia superar as excessivas e tradicionais especializações.

No entanto, apesar de todo esse percurso ter decorrido de modo a não contemplar a verdadeira crítica sobre a necessidade de uma ação interdisciplinar e muito mais como justificativa da relegitimação do discurso cientifizante/tecnocrático que se encontrava comprometido, a interdisciplina também apareceu nos setores anticapitalistas. O entendimento destes era de que a interdisciplina poderia modificar as formas de atividade científica, a fim de diminuir o isolamento do trabalho intelectual, assim como a relativa hierarquização das categorias profissionais, que acontece em decorrência desse tipo de prática isolacionista.

Contemporaneamente, essa discussão tomou uma proporção imensurável, já que esta- mos imersos numa realidade onde a informação, os meios de comunicação, enfim, o fácil acesso à ciência com todo seu aparato, mostrase cada vez mais intenso, transmitindo ao homem uma sensação de angústia e mal-estar, ao se deparar com uma natureza cada vez maior e mais complexa, resultado dos conflitos inerentes ao processo histórico que permitiram-lhe superar modos de organização social anteriores à sua. No entanto, não é necessário perpetuar esses conflitos, mas deve-se tentar superá-los, desmistificando as contradições que advém deles ${ }^{13}$.

Diante dessa atual realidade, a única alternativa, ou pelo menos a mais provável, é tentar encontrar um canal onde se inter-relacionem mais de uma área científica, ou seja, um mecanismo capaz de manter os mais variados conhecimentos numa relação de ajuda mútua, estabelecendo várias formas de se deparar e também poder descrever as experiências surgidas. O próprio diálogo com a realidade numa sociedade como a nossa, complexa, heterogênea e conflitiva por constituição, possibilita nossa aproximação com esses conflitos e interseções entre diversas disciplinas, entendendo-os não como defeitos, na busca de uma perfeição através da superação de supostas "anomalias", mas características historicamente determinadas.

Sabe-se que tentar romper com essa lógica de disciplinas estanques nos levaria à necessidade de elaboração de novos códigos, os quais requerem a possibilidade de enfrentar alguns desafios, segundo Proust ${ }^{14}$. Este autor realiza um levantamento de tais obstáculos. Primeiro, o "espírito de paróquia", ou seja, uma certa tendência em dar valor excessivo à sua metodologia em detrimento das demais, desqualificando as diferentes. Segundo, a "perda informacional" que é entendida pelo profissional como uma ameaça de perda das suas especificidades e, a partir daí, uma perda de informação e conseqüente banalização. Terceiro, o "conservadorismo institucional", que se refere ao descrédito das instituições em relação à transgressão de fronteiras do conhecimento. Por último, o "conservadorismo individual", gerador de um sentimento desconfortável, ao imaginar-se invadido, ameaçado em seu próprio território e, ao mesmo tempo, com receio de adentrar territórios alheios.

Os serviços de saúde precisam estar organizados de maneira a contemplar a possibilidade de integração entre seus recursos humanos, evitando uma organização individualista e hierárquica. Desta forma, se abririam para um mo- 
delo mais amplo de cuidado, em contraposição a um modelo tradicional.

Diante desse contexto, práticas interdisciplinares têm percorrido uma trajetória relevante do ponto de vista histórico-social, o que leva à afirmação de que nos dias atuais finalmente foram incorporadas como mais uma razão da modernidade. Em alguns momentos, tornaramse formas de legitimação de práticas instituídas; em outros, verdadeiros questionamentos críticos sobre esta mesma modernidade.

Para nós, o conceito de interdisciplinaridade está ligado a uma visão de sujeito que deve ser compartilhado pelas pessoas que buscam realizar este trabalho (sujeito integral). País ${ }^{15}$ nos introduz neste ponto de vista quando escreve: "Este novo espaço discursivo, esta nova região teórica, possibilita a comunicação interdisciplinar e a produção de uma nova ordem do saber, em que uma concepção acerca do sujeito é compartilhada por todas as disciplinas".

A interdisciplinaridade também inclui, para os sujeitos que se propõem a realizá-la como prática, o modo pelo qual lidam com a alteridade. Enfim, é a partir do viver esta experiência com o outro que se dará a constituição de uma circulação e troca de conhecimentos. Estar aberto ao outro ou restrito a este contato relaciona-se diretamente com a disponibilidade de "escutar" outros saberes e inclusive buscá-los, pois o reconhecimento do outro leva à percepção dos seus próprios limites, bem como a uma abertura à contribuição deste. E esta vivência da alteridade muitas vezes faz surgir questionamentos a respeito de si mesmo, como afirma Laplantine ${ }^{16}$ :

A experiência da alteridade (e a elaboração dessa experiência) leva-nos a ver aquilo que nem teríamos conseguido imaginar, dada a nossa dificuldade em fixar nossa atenção no que nos é habitual, familiar, cotidiano, e que consideramos 'evidente'.

É assim que a busca de um atendimento realmente integral em saúde perpassa por diversas questões, algumas das quais ligadas diretamente ao âmago da racionalidade ocidental moderna. As mudanças das práticas profissionais, relacionadas ao modo como estes sujeitos encaram e vivem suas disciplinas, poderiam mudar disposições arraigadas na sociedade. Poderiam até contradizer a maneira como o conhecimento é construído, trazendo esta construção para um contexto histórico e não a tomando como inerente. Se não exatamente contradizendo, pelo menos relativizan- do, ao demonstrar a genealogia do caráter absoluto do campo científico.

\section{O PROGRAMA}

Levando em consideração o que é exposto na literatura científica sobre o Transtorno de Personalidade Borderline, o Programa de Atendimento a Portadores de Transtorno de Personalidade Emocionalmente Instável do Tipo Limítrofe do Ambulatório Melanie Klein, localizado no Hospital Psiquiátrio São Pedro, busca desenvolver uma abordagem terapêutica mais ampla com base na interdisciplinaridade e na integralidade da atenção ao sujeito. Este programa constitui-se em torno de quatro eixos, que poderiam ser assim descritos:

1 - psicoterapia individual de orientação analítica;

2 - grupoterapia de orientação analítica;

3 - tratamento farmacológico;

4 - intervenções sociais.

A concomitância da terapia individual e de grupo constitui a chamada terapia combinada. Segundo Porter ${ }^{17}$, "seu valor único reside na capacidade que tem de coordenar as propriedades terapêuticas da psicoterapia individual e da psicoterapia de grupo".

A psicoterapia individual permite a exploração intrapsíquica profunda e a discussão de segredos. Nesta modalidade de tratamento são reativadas as relações objetais primitivas, permitindo a integração dos aspectos dissociados da personalidade ${ }^{10,18}$.

A grupoterapia permite a exploração das transferências múltiplas, a resolução das resistências interpessoais, proporciona novos modelos de identificação e apoio ao ego, bem como fornece um "laboratório" para a vivência de novos comportamentos. Para pacientes com este transtorno, "a terapia grupal limita a raiva, administra a atuação e impede o abandono prematuro da terapia" 17 .

O tratamento farmacológico para esse transtorno ainda não está bem definido. ${ }^{2}$ Ele geralmente tem como principal objetivo controlar as manifestações clínicas (sintomáticas), buscando o controle da impulsividade e da agressividade e estabilização do humor.

A intervenção social constitui-se de uma estratégia essencial no tratamento do paciente Borderline. Segundo Gabbard ${ }^{5}$, intervenções familiares podem ser necessárias para que o tratamento tenha sucesso, sendo o primeiro passo a identificação do papel das interações familiares na patogênese e manutenção da sintomatologia do paciente. Todavia, identificamos a ne- 
cessidade de compreender as interações do paciente Borderline em outros espaços sociais como escola, trabalho, comunidade entre outros. Neste sentido, o interventor social tem como propósito ajudar familiares, colegas e amigos a lidarem com as dificuldades do paciente durante o processo terapêutico, bem como ajudar na construção de uma rede social de apoio ao sujeito.

O propósito de desenvolver uma abordagem terapêutica interdisciplinar, de atenção integral ao paciente Borderline, colocou os usuários do Programa de Atendimento a Portadores de Transtorno de Personalidade Emocionalmente Instável do Tipo Limítrofe do Ambulatório Melanie Klein, localizado no Hospital Psiquiátrio São Pedro, em evidência, fazendo destes os principais atores desta investigação.

Acompanhando e observando as relações estabelecidas por estes sujeitos em diferentes contextos sociais e terapêuticos, passamos a descrever o relato de dois casos clínicos atendidos no programa.

As pacientes portadoras do Transtorno de Personalidade Emocionalmente Instável do Tipo Borderline, (segundos os critérios diagnósticos do DSM-IV) puderam se beneficiar de uma intervenção interdisciplinar efetiva, sendo que ambas mantinham-se em tratamento há mais de dois anos no SSMMK sem uma melhora clínica satisfatória. Mantinham-se com o comportamento impulsivo, hetero e auto-agressivo, sintomas depressivos e dificuldade para aderir ao tratamento proposto.

Estas duas pacientes que participaram plenamente da modalidade de tratamento proposta, apresentavam situação semelhante: R, 36 anos, encontrava-se em tratamento no AMK há seis anos, sem apresentar melhoras significativas em sua sintomatologia e M, 41 anos, encontrava-se em tratamento há quatro anos, também sem apresentar nenhuma evolução.

\section{RELATOS}

R.M.D., 39 anos, natural de Porto Alegre, solteira, desempregada, católica, grau de instrução $2^{\circ}$ grau completo.

Início dos sintomas depressivos aos 17(dezessete) anos de idade, dentre eles: desânimo, letargia, despersonalização; seguido de delírios de ruína, o que culminou com internação psiquiátrica. Apresentou pouca resposta ao tratamento farmacológico instituído. Já fez uso de fluoxetina, imipramina, carbamazepina, ácido valpróico, carbonato de lítio, clorpromazina, diazepan, E.C.T., sem eficácia clínica. Tais sintomas se mantiveram de forma crônica e houve mais duas internações ao longo dos últimos 20 (vinte) anos que duraram em média 60(sessenta) dias.

Trabalhou como secretária em uma empresa. Estabeleceu-se em vários empregos, sem condições de mantê-los. Teve um namorado por 8(oito) anos, com o qual estabelecia uma relação paterna, já que o mesmo era bem mais velho e assumia um papel de cuidador.

É a única dos 7(sete) irmãos que mora até hoje com os pais, mantendo com eles vínculos conflituosos. A família descreve-a como isolada e chorosa desde criança. Consultava muitos médicos, mas não se mantinha em tratamento medicamentoso por mais de dois meses, já que desenvolvia efeitos colaterais. A mãe é deprimida e realizava acompanhamento psiquiátrico.

Foi referida ao A.M.K. em 2000, sendo encaminhada pela Unidade Básica de Saúde do bairro. $\mathrm{Na}$ avaliação, apresentava-se com sintomas de ansiedade, depressão, melancolia, ideação suicida, múltiplas queixas somáticas, insônia, inapetência, hipersexualidade, despersonalização e delírios de ruína.

Outra vez o tratamento farmacológico mostrou-se ineficaz, seguindo mesmo assim com antidepressivo, estabilizador de humor e psicoterapia individual semanalmente. Em março de 2001, foi encaminhada ao programa para pacientes borderline, iniciando então na grupoterapia e mais tarde com intervenções sociais (visita domiciliar "VD", ambiente de trabalho e busca de novas possibilidades de trabalho). Concomitantemente à intervenção interdisciplinar, optou-se por nova abordagem farmacológica. A medicação foi substituída por Olanzapina $10 \mathrm{mg} /$ dia. A melhora clínica mostrou-se efetiva, com estabilização do humor, controle dos sintomas psicóticos, ideação suicida e de agressividade. Os terapeutas e o próprio grupo de pacientes evidenciou a melhora de R.M.D., mas a mesma apresentava dificuldades de reconhecer seus avanços. Passou a participar efetivamente das sessões, tendo "insights", melhorando interações sociais, estabelecendo um grupo de amigos com os quais desenvolvia atividades de lazer, chegando a solicitar um resgate das atividades profissionais. Ressalta-se a adesão ao tratamento e melhora da capacidade de empatia com os outros participantes do grupo. 


\section{DIAGNÓSTICO DIFERENCIAL}

\section{Depressão maior}

2. Distimia

3. Transtorno Bipolar tipo II

Apesar de preencher critérios clínicos tanto para depressão maior como para distimia, considera-se que, além dos sintomas característicos de transtorno de humor, a paciente apresenta vazio existencial, padrões de relacionamento instáveis, impulsividade, autodestrutividade, difusão de identidade, característicos da personalidade borderline.

Quanto à labilidade afetiva e à hipersexualidade, não preenche critérios suficientes para transtorno bipolar.

A grupoterapia consistiu de sessões semanais de uma hora e trinta minutos em co-terapia entre um residente médico e uma psicóloga. $\mathrm{O}$ grupo era composto por cinco membros, e o enfoque recebido era de orientação analítica.

Os atendimentos individuais também eram feitos por médicos residentes e psicólogos, porém não os mesmos terapeutas da grupoterapia. Estes atendimentos consistiam em revisões clínicas semanais para controle da medicação e abordagem psicoterápica.

As intervenções sociais ocorriam sem periodocidade definida, variando semanalmente ou quinzenalmente de acordo com a necessidade do caso. Elas consistiam em visitas domiciliares, escolares, ao ambiente de trabalho e a outros espaços comunitários, realizados por uma terapeuta ocupacional e uma professora de educação física.

Todos os profissionais envolvidos neste projeto de atendimento integral em saúde mental reuniam-se semanalmente com a finalidade de discussão dos casos e reavaliação da proposta terapêutica.

\section{METODOLOGIA}

Para avaliar os resultados obtidos no tratamento proposto, os autores utilizaram a observação da evolução de dois casos clínicos e, após, descreveram a experiência obtida pela prática interdisciplinar. Os resultados obtidos justificaram a implantação e continuidade do Programa no Ambulatório Melanie Klein do Hospital Psiquiátrico São Pedro.

A coleta dos dados foi realizada a partir da triangulação de técnicas, como sugere Tri$v_{i n ̃ o s}{ }^{18}$, que propõe que se relacionem diferen- a complexidade da realidade do contexto em estudo. As técnicas utilizadas foram a observação participante, a análise documental (prontuários) e a análise de discurso, considerando tanto as falas produzidas no contexto terapêutico quanto no campo social

A observação participante possibilitou o acesso a uma gama de dados, inclusive àqueles que os pesquisadores não previram no início do estudo ${ }^{19}$ e realizou-se através do contato direto dos pesquisadores-terapeutas com o fenômeno observado, obtendo-se desta forma as informações sobre a realidade ${ }^{20}$.

Toda a dinâmica do processo vivido tanto nos espaços terapêuticos, quanto nos espaços sociais, como comentários, expressões e manifestações dos pacientes e dos sujeitos diretamente envolvidos com ele, constituíram-se enquanto material de análise neste estudo. A própria natureza interdisciplinar da proposta possibilitou a observação dos múltiplos contextos de vida desses sujeitos.

O rigor da análise das informações coletadas tornou-se um desafio para contribuir com a construção do conhecimento no campo da Saúde Mental. Neste sentido, dentre os procedimentos, foi realizada a discussão e reflexão dos paradigmas e pressupostos éticos, políticos e teóricos que embasaram as ações dos pesquisadores-terapeutas. Assim, foram construídas as seguintes categorias de análise:

1. relacionamento interpessoal;

2. interesses e atividades ocupacionais e de lazer;

3. autonomia.

Todavia, sentiu-se a necessidade do estabelecimento de critérios quantitativos de análise, tais como:

4. número de internações;

5. tentativas de suicídio;

6. procura por serviços de emergência.

\section{RESULTADOS E DISCUSSÃO}

As intervenções sociais, que foram incluídas no planejamento terapêutico do grupo em questão, como uma possibilidade de se estender $o$ atendimento ao qual nos referimos, tão amplo e complexo por sua natureza, se mostraram eficazes, apesar de terem sido realizadas em uma pequena amostra de pacientes (em função da peculiaridade de cada caso e da própria estrutura da equipe que ainda se construía).

A visita domiciliar foi uma das estratégias de aproximação com essa realidade, já que se evidencia como elemento constitutivo e cons- 
trutor do processo de intervenção profissional. Foi utilizada para conhecer a realidade social do paciente, da família, observando in locus o espaço do cotidiano, identificando as relações, ações e seus significados e desvelando elementos que puderam complementar nosso objeto de investigação. Buscou-se, então, "com curiosidade e espírito investigativo "21, capturar o todo, "reestruturando-o através do nosso olhar vigilante, ocupado..., capaz de encontrar a verdade daquela realidade, não a verdade que se acredita ou quer que seja" 21 .

As visitas se estendiam não somente ao domicílio, mas a outros espaços de circulação da pessoa em questão, onde se observava a necessidade de uma melhor reestruturação de suas inter-relações, assim como uma aproximação no contexto social mais amplo (escola, trabalho, lazer, etc.).

Considerando então as categorias de análise apresentadas anteriormente, detectou-se melhora tanto nos critérios qualitativos apontados como nos quantitativos:

$\mathrm{R}$, durante o ano de 2002 (fase inicial da proposta interdisciplinar), sentiu-se acolhida pela equipe, de modo a aceitar a introdução de uma nova medicação (olanzapina), pois até então se mostrava resistente à farmacoterapia. Observou-se também uma ampliação em seus interesses sociais e de trabalho.

$M$, neste mesmo período, melhorou consideravelmente seus relacionamentos familiares e sociais, diminuindo a agressividade que dirigia a seus filhos e a seu marido, assim como o modo impulsivo como lidava com as demais pessoas (tendo inclusive agredido uma terapeuta anterior). Aumentou seus interesses sócio-ocupacionais, vindo a participar de atelier de artesanato e de pintura.

\section{CONCLUSÕES}

O conhecimento científico vem buscando cada vez mais aprofundamento e abrangência de áreas na sua produção. Esta forma do conhecer a partir de diferentes disciplinas se revelou como um dos "carros-chefes" deste estudo, partindo de um referencial teórico que passeou por diferentes áreas do conhecimento - da clínica às ciências sociais. Neste sentido, o presente trabalho constituiu-se como interdisciplinar, de forma que todos os conhecimentos envolvidos conseguiram dialogar. Acreditamos que não poderia ser diferente, pois a vida cotidiana do paciente Borderline apresenta-se como multifacetada em sua complexidade, de modo que não poderíamos abordá-la a partir de uma só disciplina.

A partir dos relatos de caso aqui apresentados pôde-se perceber que a abordagem interdisciplinar possibilitou uma melhora integral desses pacientes. Observou-se não apenas uma estabilização dos sintomas clínicos psiquiátricos, mas principalmente a aquisição de um nível de funcionamento mais satisfatório. A apresentação de modelos de identificação contribuiu para o fortalecimento do ego e desenvolvimento segundo conceitos kleinianos de relações objetais mais estáveis. A coesão e cuidado dos terapeutas, trabalhando em equipe, proporcionou a construção de um "setting" continente no qual esses sujeitos puderam sentir-se seguros para deparar-se com suas dificuldades e mudanças.

É importante ressaltar a idéia de estabilidade que um tratamento bem organizado transmite ao paciente Borderline. Este sente-se confiante e acolhido ao perceber que conta com uma equipe de profissionais coesa, bem como um serviço apto a corresponder às suas necessidades.

Enfatizamos o fato desse estudo constituir um projeto piloto ainda em estruturação, o que nos ocasionou uma amostra pequena e um plano terapêutico interdisciplinar em construção.

A experiência obtida na implantação do Programa de Abordagem Interdisciplinar no Tratamento do Transtorno de Personalidade Borderline no Ambulatório Melariie Klein do Hospital Psiquiátrico São Pedro alerta para a importância da prática interdisciplinar de tratamento no campo da saúde mental, demonstrando a necessidade de percebermos o ser humano em sua integralidade.

\section{REFERÊNCIAS BIBLIOGRÁFICAS}

1. Winnicott D. Privação e Delinqüência. Porto Alegre: Martins Fontes, 1987.

2. Gunderson JG, Phillips KA. Transtornos de Personalidade. In: Kaplan H e Sadock B. Tratado de Psiquiatria. Vol. 2. Porto Alegre: Artes Médicas; 1999. p. 1542-82.

3. Classificação de Transtornos Mentais e de Comportamento da Classificação Internacional de Doenças - Décima Edição: Descrições Clínicas e Diretrizes Diagnósticas. Coordenação Organização Mundial de Saúde. Porto Alegre: Artes Médicas, 1993.

4. American Psychiatric Association. Diagnostical and Statistical Manual of Mental Disorders, Fourth Edition, Washington, DC, American Psychiatric Association, 1994. [Manual Diagnóstico e Estatístico de Transtornos Mentais. trad. Cláudia Dornelles; - 4. ed. rev. - Porto Alegre: Artmed, 2002.]

5. Gabbard GO. Psiquiatria Psicodinâmica. $2^{\underline{a}}$ ed. Porto Alegre: Artmed, 1998.

6. Gunderson JG, Phillips KA. A current view of the interfa- 
ce beteween borderline personality disorder and depression. Am J Psychiatry 1991;148:967-975.

7. Gunderson JG, Zanarini MC, Kisiel CL. Borderline personality disorder: a review of data on DSM-III-R descriptions. Journal of Personality Disorder 1991; 5:340-352.

8. Bleichmar, Bleichmar. A psicanálise depois de Freud: teoria e clínica. Porto Alegre: Artmed, 1992.

9. Kernberg OF, Selzer MA, Koenigsberg HW, Carr AC, Appelbaum AH. Psicoterapia psicodinâmica de pacientes borderline. Porto Alegre: Artes Médicas, 1991.

10. Brasil. Congresso Nacional. Constituição da República Federativa do Brasil. Promulgada em 5 de outubro de 1988.

11. Mattos RA. Os Sentidos da Integralidade: algumas reflexões acerca de valores que merecem ser defendidos. In Pinheiro R, Mattos RA (org.). Os sentidos da integralidade na atenção e no cuidado à saúde. Rio de Janeiro: UERJ, IMS: ABRASCO; 2001.

12. Castoriadis $C$. $A$ instituição imaginária da sociedade. Rio de Janeiro: Paz e Terra; 1982.

13. Jantsch $A P$, Bianchetti $L$ (org.). Interdisciplinaridade: para além da filosofia do sujeito. Petropólis: Vozes, 2001

14. Proust J. A interdisciplinaridade nas ciências cognitivas. Revista Tempo Brasileiro 1993; abr.-jun., 113:. 97-118.

15. País A. Interdisciplina e transdiciplina na clínica dos transtornos do desenvolvimento infantil. Escritos da Criança - Centro Lydia Coriat 1996; n. 4.

16. Laplantine F. Aprender Antropologia. São Paulo: Braziliense; 2000.

17. Porter K. Psicoterapia individual e grupal combinadas. In Kaplan, Sadock. Compêndio de Psicoterapia de Grupo. $3^{a}$ ed. Porto Alegre: Artes Médicas; 1996. p. 262-9.

18. Triviños ANS. Introdução à Pesquisa em Ciências Sociais. São Paulo: Atlas; 1987.

19. Becker H. Métodos de Pesquisa em Ciências Sociais. 4ed. São Paulo: Hucitec, 1999.

20. Minayo MC (org.). Pesquisa Social: teoria, método e criatividade. Petrópolis, RJ: Vozes;1994.

21. Amaro ST. Visita domiciliar: orientações para uma abordagem complexa. In: Desalunieres J (org.). Fenômeno: uma teia complexa de relações. Porto Alegre: EDPUCRS; 2000 .

\section{RESUMO}

Introdução - Os transtornos de personalidade são uma classe diagnóstica em Psiquiatria cujo tratamento não está ainda claramente definido. Devido ao grande número de alterações que o transtorno de personalidade borderline ocasiona na vida de seus portadores, propomos um atendimento interdisciplinar integrado. Esta proposta organiza-se em quatro eixos: psicoterapia individual de orientação analítica, grupoterapia de orientação analítica, psicofarmacoterapia e intervenções sociais.

Metodologia - Este estudo baseia-se na descrição da experiência obtida pelos autores na implantação de um Programa de Abordagem Interdisciplinar no Tratamento do Transtorno de Personalidade Borderline, utilizando como exemplo dois relatos de caso sucintos, a respeito de duas pacientes com transtorno de personalidade borderline. Foram avaliados critérios qualitativos para descrever a melhora obtida pelas pacientes através do Programa (relacionamen- to interpessoal, interesses e atividades ocupacionais e de lazer, autonomia) e quantitativos (número de internações, tentativas de suicídio, procura por serviços de emergência).

Resultados e discussão - As intervenções sociais mostraram-se eficazes ao incrementar as terapêuticas já tradicionalmente colocadas. Houve meIhoras relacionadas aos critérios acima colocados.

Conclusão - Os resultados encontrados alertam-nos para a necessidade de observarmos os pacientes em seus diversos contextos, de forma a apresentar intervenções que dêem conta dessas múltiplas dimensões.

Descritores: Transtornos de personalidade borderline, interdisciplinaridade, tratamento.

\section{ABSTRACT}

Introduction - In Psychiatry, personality disorders are still a complex diagnostic class. There is no clearly defined treatment for such disorders. Due to the great number of complications this kind of disorder causes in the individual, we propose an interdisciplinary and integrated treatment. Our proposal has four axes of intervention: individual analytical psychotherapy, analytical group therapy, psychopharmacotherapy and social interventions.

Methods - This study presents two brief reports on cases with borderline disorder. Several personality criteria have been evaluated. We assessed various criteria (quality of interpersonal relations, work and leisure activities, autonomy, suicide attempts, seeking emergency care).

Results and discussion - The social interventions played an important role by adding to the traditional treatment. Both patients have benefited from the treatment.

Conclusion - The results found call our attention to the importance of seeing the individual as a whole, and organizing interventions that can cover the various dimensions of life.

Keywords: Borderline disorder, interdiciplinarity, treatment.

Title: Program for an interdisciplinary approach in the treatment of borderline personality disorder - report on the experience at the Melanie Klein out-patient clinic at Hospital Psiquiátrico São Pedro

Endereço para correspondência:

Pablo de Oliveira Corrêa

Rua Demétrio Ribeiro, 654/203

90010-312 - Porto Alegre - RS

Fones: (51)3226.7391/9116.3202

E-mail: pablo.correa@via-rs.net

Copyright (C) Revista de Psiquiatria do Rio Grande do Sul - SPRS 


\title{
Tabela 1
}

Critérios diagnósticos segundo DSM-IV

\section{DSM-IV}

301.83 Transtorno de Personalidade Borderline

Um padrão global de instabilidade dos relacionamentos interpessoais, da auto-imagem e dos afetos e acentuada impulsividade, que se manifesta no início da idade adulta e está presente em uma variedade de contextos, indicado, por, no mínimo, cinco dos seguintes critérios:

(1) esforços frenéticos no sentido de evitar um abandono real ou imaginário. Nota: Não incluir comportamento suicída ou automutilante, coberto no Critério 5.

(2) um padrão de relacionamentos interpessoais instáveis e intensos, caracterizado pela alternância entre extremos de idealização e desvalorização

(3) perturbação da identidade: instabilidade acentuada e resistente da auto-imagem ou do sentimento de self

(4) impulsividade em pelo menos duas áreas potencialmente prejudiciais à própria pessoa (p. ex., gastos financeiros, sexo, abuso de substâncias, direção imprudente, comer compulsivo). Nota: Não incluir comportamento suicida ou automutilante, coberto no Critério 5.

(5) recorrência de comportamento, gestos ou ameaças suicidas ou de comportamento automutilante

(6) instabilidade afetiva devido a uma acentuada reatividade do humor (p. ex., episódios de intensa disforia, irritabilidade ou ansiedade geralmente durando algumas horas e apenas raramente mais de alguns dias)

(7) sentimentos crônicos de vazio

(8) raiva inadequada e intensa ou dificuldade em controlar a raiva (p. ex., demonstrações freqüentes de irritação, raiva constante, lutas corporais recorrentes)

(9) ideação paranóide transitória e relacionada ao estresse ou graves sintomas dissociativos

\section{Tabela 2}

Critérios diagnósticos segundo CID-10

\begin{abstract}
CID-10
F60.3 Transtorno de personalidade emocionalmente instável

Um transtorno de personalidade no qual há uma tendência marcante a agir impulsivamente sem consideração das conseqüências, junto com a instabilidade afetiva. A capacidade de planejar pode ser mínima e acessos de raiva intensa podem com freqüência levar à violência ou a "explosões comportamentais"; estas são facilmente precipitadas quando atos impulsivos são criticados ou impedidos por outros. Duas variantes desse transtorno de personalidade são especificadas e ambas compartilham esse tema geral de impulsividade e falta de autocontrole.
\end{abstract}

F60.31 Tipo borderline (limítrofe)

Várias das características de instabilidade emocional estão presentes; em adição, a auto-imagem, objetivos e preferências internas (incluindo a sexual) do paciente são com freqüência pouco claras ou perturbadas. Há em geral sentimentos crônicos de vazio. Uma propensão a se envolver em relacionamentos intensos e instáveis pode causar repetidas crises emocionais e pode estar associada com esforços excessivos para evitar o abandono e uma série de ameaças de suicídio ou atos de autolesão (embora esses possam ocorrem sem precipitantes óbvios). 